\title{
MAPEAMENTO DO PERFIL DO ENGENHEIRO DE PRODUÇÃO E CIVIL NO MERCADO DE TRABALHO
}

Ângelo Antonio Rocha Xavier - angelorxavier@ hotmail.com

Universidade Federal de Alagoas - Campus Sertão

Rua Marcildo Barros A. Luz, 191. Copo de Cristal

56000-000 - Salgueiro - Pernambuco

Vivian Stefanny Rodrigues da Silva - vivian_stefanny@ hotmail.com

Universidade Federal de Alagoas - Campus Sertão

Rua João Pacheco Delgado, 171. Centro

56460-000 - Petrolândia - Pernambuco

Jailson dos Santos Vieira - jailsonsantos347@ gmail.com

Universidade Federal de Alagoas - Campus Sertão

Rua Luís Luna Torres, 106. Bairro Novo

57480-000 - Delmiro Gouveia - Alagoas

Guilherme Henrique de Oliveira Silva - guilhermeout@ hotmail.com

Universidade Federal de Alagoas - Campus Sertão

Rua Pedro Gomes de Menezes, 123. Palmeirão

57480-000 - Delmiro Gouveia - Alagoas

Rogério de Jesus Santos - rogerio.santos@ delmiro.ufal.br

Universidade Federal de Alagoas - Campus Sertão

Rua Jasiel de Brito Cortes, 320, condomínio Recanto dos ventos, bloco Alísios 102 49095-780 - Aracaju - Sergipe

Resumo: O presente estudo busca compreender e explanar os principais e mais solicitados requisitos para a obtenção de um emprego no mercado de trabalho atual. Essa análise teve como objetivo identificar habilidades e atribuições inerentes a profissão de Engenharia Civil e Engenharia de Produção, de modo a atender o mercado de trabalho como profissionais que tenham a prática de desenvolver e transferir a aplicabilidade do conhecimento adquirido e de critérios solicitados. A partir do levantamento dos principais requisitos laborais, foi percebido que os profissionais precisam estar qualificados não somente na área técnica, para atender as necessidades produtivas da empresa, como também na conduta, pois é importante que se acompanhe o ritmo das mudanças e assuma uma postura condizente com as mesmas. Espera-se que, com esta análise, estudantes e engenheiros sejam beneficiados com as informações aqui apresentadas através de um levantamento dos critérios mais exigidos pelas empresas para os engenheiros civis e de produção obter uma vaga de emprego no mercado de trabalho atual.

Palavras-chave: engenharias, mercado de trabalho, perfil profissional. 


\section{INTRODUÇÃO}

É inevitável, enquanto estudante de graduação, não pensar no mercado de trabalho cada vez mais, quando o curso se encaminha para o final, principalmente, em cursos de engenharia. Esses nos quais o mercado cada dia torna-se mais exigente quanto aos requisitos para efetuar a contratação de engenheiros recém-formados.

No final da graduação, muitos universitários já aspiram sua entrada no campo profissional por diversos motivos. Enquanto, outros ainda pensam em seguir os estudos em cursos de especializações, muitas vezes, visando uma carreira acadêmica longe de indústrias, escritórios ou canteiros de obra. Porém, seja qual for a decisão que o aluno escolha, no final de seu curso, ele terá que tomar muitas decisões para seu futuro. Pois, seu objetivo maior é ser o mais bem sucedido possível. Nesse contexto, as universidades tem como objetivo proporcionar subsídios teóricos para os graduandos, tornando assim aptos a terem conhecimento em todas as áreas da engenharia cursada. Contudo, o ensino superior deixa "brechas" quanto as questões práticas exigidas pelos cursos. Uma vez que, o corpo docente e o próprio sistema da Universidade não orientam os estudantes, no que diz respeito ao enfrentamento das dificuldades da vida profissional para os recém-formados.

De acordo com as Diretrizes Curriculares Nacionais do Curso de Graduação em Engenharia (DCNs de Engenharia), instituídas por meio da Resolução CNE/CES n ${ }^{\circ} 11$, de 11 de março de 2002, o objetivo para o perfil ideal de um engenheiro recém-formado, conforme explicitado no Parecer CNE/CES n ${ }^{\circ}$ 1.362/2001 é:

O novo engenheiro deve ser capaz de propor soluções que sejam não apenas tecnicamente corretas, ele deve ter a ambição de considerar os problemas em sua totalidade, em sua inserção numa cadeia de causas e efeitos de múltiplas dimensões. Não se adequar a esse cenário procurando formar profissionais com tal perfil significa atraso no processo de desenvolvimento (MEC, 2001).

Os dados colhidos para compor esta pesquisa irão mostrar a necessidade do aluno de engenharia sempre procurar conhecimento além da universidade. Até por que, como será exposto ao longo deste trabalho o "ter algo a mais" no currículo, muitas vezes, pode ser determinante para conseguir uma vaga de emprego. Este diferencial pode ser, dentre tantas opções: um domínio de língua estrangeira, domínio em diversos softwares ou mesmo a questão da experiencia na área escolhida dentro da engenharia.

Nesse sentido, o presente artigo vem discutir uma visão geral de perfil de profissionais da engenharia civil e produção que são almejados pelo mercado de trabalho. Os dados que serão apresentados, constam desde pesquisas realizadas em sites que ofertam vagas de empregos a conversas com engenheiros que já estão há algum tempo inseridos no mercado e assim compartilharam as experiências por eles vivenciados.

\section{FUNDAMENTAÇÃO TEÓRICA}

É perceptível a necessidade de conhecimento dos diversos aspectos para se ter um início, permanecer e também progredir em uma carreira profissional. Diante disso, é muito importante analisar o presente artigo e buscar novas ideias de ações que atendam às novas necessidades.

Segundo Pinto et al (2004), no ano de 2004 o mercado para engenharia civil vinha se apresentando com escassez devido a recessão e a falta de crescimento econômico. Assim fazendo que a procura pelo curso nas universidades fossem baixas, gerando assim desinteresse pela profissão e levando a mudar de área de atuação.

No entanto, no ano de 2007 foi lançado o Programa Minha Casa Minha Vida (PMCMV), que tinha como função aquecer o sistema produtivo da construção e diminuir o déficit 
habitacional. O PMCMV fez com que houvesse a procura pelos cursos de engenharia civil com intuito da estabilidade financeira, devido ao momento em que se encontrava a economia e os investimentos na construção civil.

$\mathrm{Na}$ etapa que procede a saída da universidade, já formado como engenheiro de produção, almeja-se a entrada no mercado de trabalho. É visto, por exemplo na UNIVASF (Universidade Federal do Vale do São Francisco) que alguns estudantes, quando obtêm algum estágio de maior destaque ou uma melhor possibilidade, já conseguem se inserir, imediatamente, numa empresa, quando saem da universidade. No entanto, outros, ainda, têm que esperar algum tempo para a primeira atividade como engenheiro (JUNIOR et al, 2012).

Outra questão também que deve ser ressaltada, é a carência de dados sobre registros de profissionais em Engenharia atuando no mercado de trabalho. Pois, os que existem certamente não contabilizam devidamente, por exemplo, os proprietários de empresas de Engenharia. Existem muitas pequenas empresas que desenvolvem atividades de Engenharia e cujos donos são os próprios engenheiros que exercem a atividade de gestor e de técnico, e que não constam dos registros como engenheiros e sim como empresários. Também subsiste uma significativa parcela de engenheiros contratados como analistas, gerentes, supervisores, entre outros, mas que exercem atividades de Engenharia ou relacionadas a estas (OLIVEIRA, et al 2012).

De acordo com Barros e Paiva (2013), o processo de formação e desenvolvimento de competências tem sido percebido como mais complexo do que a mera qualificação do profissional. No mercado atual existe uma postura profissional cada vez mais exigente. Esse que vai desde uma formação acadêmica de qualidade até a manutenção de aprendizado contínuo.

A evolução da engenharia está atrelada ao desenvolvimento das sociedades, com o passar do tempo, veem suas necessidades e demandas específicas renovadas, precisando adaptar-se aos contextos sociais, políticos e econômicos do momento (BAHIA E LAUDARES, 2013). Logo, como por consequência faz com que a competitividade se torne mais elevada do que o comum. O Conselho Federal de Engenharia e Agronomia (Confea) revela que nos anos recentes aproximadamente 100 mil novos engenheiros desembarcaram no mercado de trabalho por ano. Esse fato revela ainda mais o quão necessário é se manter atualizado no mercado de trabalho atual, de modo a ter maior potencial de emprego.

O cenário mostra que a formação do Engenheiro deve ser muito mais ampla do que era em tempos passados. Uma vez que, nessa época específica a formação que interessava era basicamente ter acesso a possíveis cursos técnicos. Mas, hoje, segundo Póvoa (2005), essa formação técnica/científica é somente um dos pré-requisitos para a atuação profissional.

Diante disso, surgiu-se o desejo de estudar e explicitar informações importantes para auxiliar engenheiros que desejam atuar no mercado de trabalho, seja esse profissional um recém-formado ou um sênior. Logo, foram indicadas e observadas algumas características e também critérios importantes no mercado de trabalho e, através disso, foi possível obter as informações referentes à necessidade de cada um dos critérios no mercado atual.

\section{METODOLOGIA}

Recolheu-se uma amostra de 40 empresas com cadastros em sites de empregos, repartidas igualmente entre Engenharia de Produção e Engenharia Civil, as quais posteriormente foram analisadas baseado nas frequências de cada critério observado. Em seguida as frequências foram utilizadas para a geração de gráficos específicos sobre cada engenharia, a fim de discorrer sobre os resultados encontrados.

Os critérios analisados para o mapeamento das vagas de emprego foram: 
- Experiência: A engenharia é uma área de conhecimento tão ampla quanto diversificada, dispondo de direcionamentos que colocam o engenheiro formado diante do mercado em que ele deseja se desenvolver. Diante disso, algumas empresas adotam critérios quanto à experiência em determinada área. Pois, a vivência nessa área agrega no potencial do engenheiro que venha a ser contratado.

- Especialização: Obter uma especialização torna o profissional cada vez mais diferenciado. Na medida em que obtém o conhecimento de muitos assuntos, os quais não foram vistos durante a graduação e também direciona melhor a área que deseja exercer sua profissão. A especialização possibilita um conhecimento mais profundo e amplo sobre uma área que possa ser exigida pelas empresas.

- Domínio de softwares: O engenheiro tem como propósito principal: a resolução de problemas. Sendo que, para isso é imprescindível, principalmente, em tempos cada vez mais modernos, que o engenheiro tenha domínio sobre os principais softwares utilizados na engenharia, a exemplo do Autodesk Revit, AutoCAD, Microsoft Project, ARENA, Microsoft Excel, e etc. As empresas priorizam profissionais com competência para trabalhar com softwares. O domínio dessas ferramentas agrega ao perfil do engenheiro, pois toda atividade se inicia e tem a sua continuidade através do material produzido por manuseio dos softwares.

- Gestão: O conhecimento em gestão é fundamental para todo engenheiro. Uma vez que, projetos e orçamentos são inerentes a qualquer ação realizada pela empresa, o que torna a parte administrativa um fator fundamental a ser desenvolvido por todo engenheiro no mercado de trabalho.

- Trabalho de campo: O trabalho de campo é, sem dúvida, a melhor ligação entre a teoria e a prática na vida profissional do engenheiro. Essa prática, detém uma força de experiência e aprendizado enorme, pois seu desenvolvimento é presente possuindo uma ação interligada. Em que, o ator principal não é o livro didático como de costume, mas sim o lugar que está sendo realizado o estágio/trabalho e utilizado como base para o conhecimento do engenheiro.

\section{RESULTADOS E DISCUSSÕES}

Os eixos das abscissas mostrados nos gráficos dentro das figuras mostradas a seguir foram categorizados de acordo com os 5 critérios escolhidos para a avaliação, os quais são: experiência, especialização, domínio de softwares, gestão e trabalho em campo. Os eixos das ordenadas foram dados em função da porcentagem máxima a ser obtida.

O Figura 1 apresenta os dados referentes as frequências obtidas de acordo com a pesquisa das empresas de Engenharia Civil. A partir da figura pode-se concluir que o trabalho em campo é o mais requisitado quando se fala em engenharia civil, e também equivale ao dobro da necessidade em relação a gestão em obras. O percentual da experiência demonstra um mercado atual que ainda preza por um profissional mais experiente, deixando de lado os recém-formados da área. O domínio de softwares está intimamente ligado à experiência, por obtermos valores tão próximos. Tais valores explicitam um mercado de trabalho que, além de necessitar de profissionais experientes, também é carente de profissionais atualizados e alinhados com as ferramentas de trabalho exigidas. Por fim, o critério que obteve a menor frequência foi a especialização, resultado esse que pode ser interpretado em um mercado que procura profissionais que possibilitem abranger o maior número de serviços possíveis. 
Figura 1 - Requisitos para Engenharia Civil

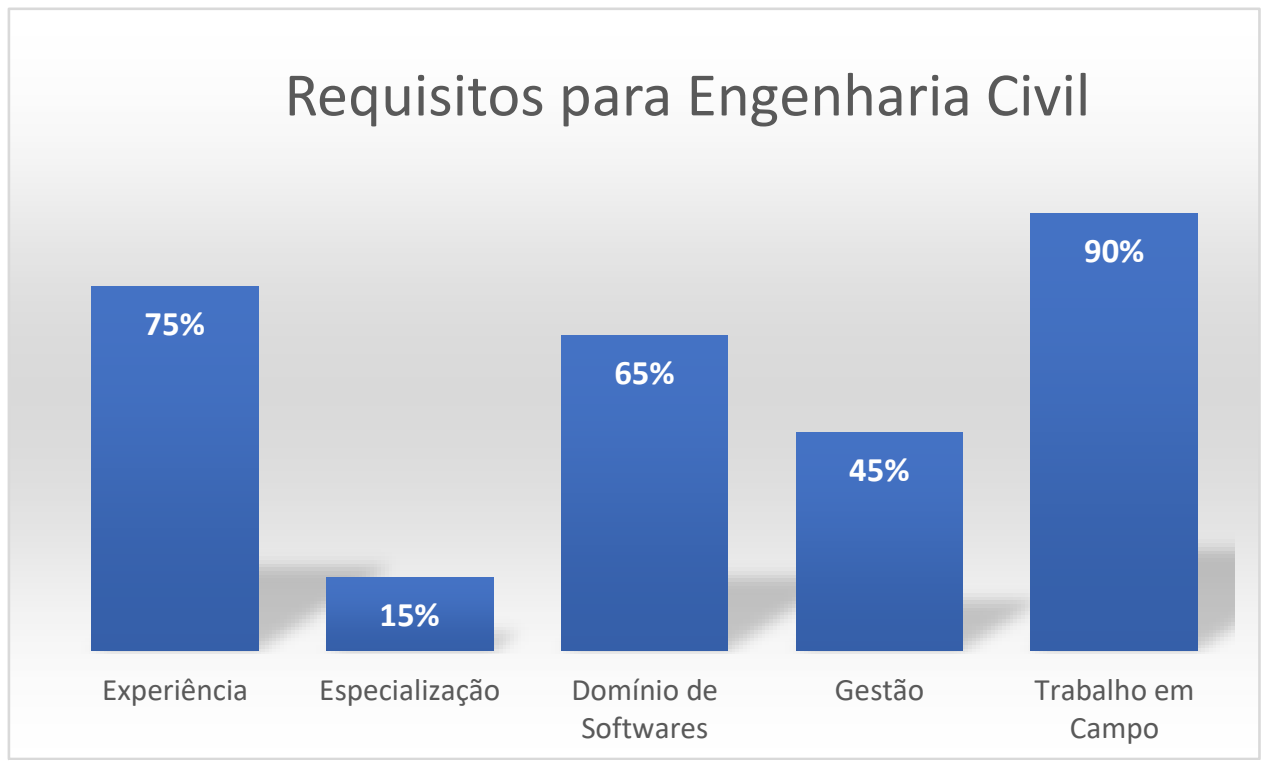

Fonte: Autores, 2020

O técnico do IPEA, Bruno Araújo descreve na sua publicação Radar nº 43 feita no site do IPEA que existe uma necessidade de um perfil mais específico de engenheiro, com mais qualificações e experiência. Conforme também declara o presidente do Sinduscon-TO, Bartolomé Garcia, que houve grandes investimentos em tecnologia no Brasil, servindo como um agente facilitador para o profissional e para a construção civil, mesmo sendo ainda muito caro absorver estas novas ferramentas.

A Figura 2 apresenta os dados referentes as frequências obtidas de acordo com a pesquisa das empresas para a Engenharia de Produção. A partir do gráfico contido na figura se pode concluir que é sempre necessário que o engenheiro da produção atue na área da gestão, sendo o requisito presente em todos os dados coletados, e evidentemente fundamental para todo engenheiro da área. A especialização também se mostra um requisito muito influente para uma contratação no setor da engenharia de produção. Em contrapartida, a experiência e o domínio de softwares demonstram ser equivalentes para esta área, tornando claro que um engenheiro de produção pode equilibrar seu currículo com pouca experiência e com domínio pouco abrangente sobre softwares. Por fim, o critério de menor frequência foi o trabalho em campo, o qual reflete a necessidade da empresa que o profissional da produção atue essencialmente na gestão. 


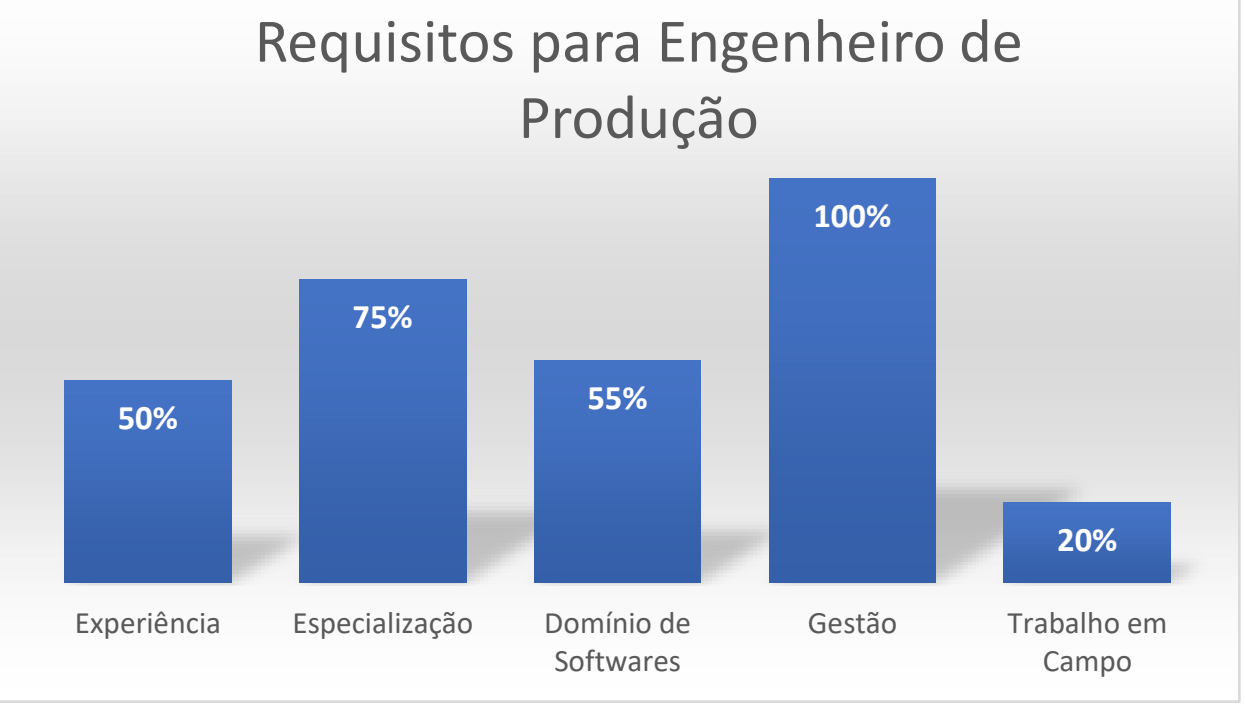

Fonte: Autores, 2020

Por atuar como elo entre o setor técnico e o administrativo, o engenheiro da produção define a melhor forma de integrar a mão de obra, equipamentos e matéria-prima para o avanço da qualidade e da produtividade (QUINTAS,2013).

\section{CONCLUSÃO}

Portanto, após as pesquisas bibliográficas, o levantamento dos dados apresentados e alguns relatos de experiências vividas foi possível transubstanciar os critérios mais solicitados para a aquisição de emprego no mercado de trabalho na área de Engenharia Civil e Engenharia de Produção.

A vida acadêmica possui limitações no que se refere a proporcionar aos discentes um vasto conhecimento do mercado de trabalho devido às amplas áreas que as profissões dispõem. Quando formado, o Engenheiro tem a dificuldade por não possuir um histórico de atuação no mercado de trabalho, tendo somente o histórico acadêmico como primeiro contato com a futura profissão. Mas, através desse estudo foi possível observar que o mercado de trabalho vai além de somente o âmbito acadêmico e exige que o engenheiro busque cada vez mais um aperfeiçoamento para obter os critérios necessários para uma vaga de emprego no mercado de trabalho.

A discrepância dos números entre as duas engenharias, Civil e Produção, foi enorme, pois cada área possui o seu perfil de atuação. Contudo e, todavia, o presente estudo relata que os critérios existem e são altamente imposto pelas empresas atualmente, o aperfeiçoamento e a busca de melhorias de aprendizado nunca serão pouco ou desnecessário. Percebeu-se que a principal habilidade do profissional de Engenharia de Produção consiste em: otimizar o uso de sistemas, evitando desperdícios, possibilitando desta maneira, a área de gestão mais desejada, diferente da Engenharia Civil onde a área de trabalho em campo foi a mais exigida com intuito de uma maior atuação nos canteiros de obras.

Entre as empresas pesquisadas na primeira análise, o maior número obtido encontra-se em trabalho de campo e o segundo maior número encontra-se no quesito da experiência, 
através desses dois dados o estudo conseguiu observar que sem a vivência no campo e sem as oportunidades. Logo, o engenheiro não possuirá experiência para conseguir uma vaga de emprego no mercado de trabalho com mais facilidade. Além de também explanar a importância do aprendizado continuo que resulta em um grande domínio de softwares, sendo esse critério o terceiro mais exigido.

Na segunda análise, referente a profissão de Engenheiro de Produção, concluímos ideias totalmente divergentes da anterior. Em que, todas as empresas ofertaram vagas para gestão e consequentemente para exercer um bom trabalho é solicitado que se tenha especializações, sendo essa a segunda maior exigência observada neste estudo.

$\mathrm{O}$ atual estudo consegue transmitir a todos os estudantes e os profissionais dessa área. Como é importante e como os mesmos precisam buscar novos horizontes de conhecimento, visando novas ideais e novos aprendizados que possam contribuir e acrescentar no progresso de uma empresa e consequentemente no progresso pessoal e profissional do Engenheiro.

\section{REFERÊNCIAS}

ARAÚJO, B. O que fazem os Engenheiros sem Carteira Assinada? Situação Ocupacional dos Formados em Engenharia a partir dos censos de 2010 e 2000. Disponível em: https://www.ipea.gov.br/portal/images/stories/pdfs/radar/160309_radar43_cap_7.pdf. Acesso em: 24 julho de 2020.

BAHIA, M. M.; LAUDARES, J. B. A Engenharia e a Inserção Feminina. In: Seminário Internacional Fazendo Gênero 10, 2013, Florianópolis. Anais. Florianópolis, 2013.

BARROS, L. E. V.; PAIVA, K. C. M. Impacto de vivências acadêmicas nas competências profissionais: percepções de egressos de um curso de mestrado em Administração. Teoria e Prática em Administração, v. 3 n. 1, 2013, pp. 96-120.

BRASIL. MEC. Resolução CNE/CES n 1.362, de 12 de dezembro de 2001. Diretrizes Curriculares Nacionais dos Cursos de Engenharia. Disponível em: http://portal.mec.gov.br/cne/arquivos/pdf/CES1362.pdf. Acesso em: 16 julho 2020.

GARCIA, B. Ética Profissional. Disponível em: http://www.creato.org.br/files/download/20161010163643_revista_crea_to_012016.pdf. Acesso em: 24 de julho de 2020 .

JUNIOR, W. W. R. de S. et al. O Mercado de Trabalho para o Engenheiro de Produção: uma Análise a Partir dos Profissionais Formados pela Univasf, 2016, João Pessoa. Anais. João Pessoa, 2016.

OLIVEIRA, V. F. de. et al. Um Estudo sobre a Expansão da Formação em Engenharia no Brasil. Revista de Ensino de Engenharia da ABENGE. Edição Especial comemorativa dos 40 anos da entidade, 2012. Disponível em: https://www.ufjf.br/observatorioengenharia/files/2012/01/ExpEng-RevAbenge.pdf. Acesso em: 28 julho 2020. 
PINTO, L. C. et al. Perspectiva do Profissional de Engenharia Civil: Tendências do Mercado de Trabalho, 2004, Brasília. Anais. Brasília, 2004.

PÓVOA, J. M.; BENTO, P. E. G. O Engenheiro, sua Formação e o Mundo do Trabalho. In: XXXIII - Congresso Brasileiro de Ensino de Engenharia, 2005, João Pessoa. Anais. Campina Grande, 2005.

QUINTAS, P. Procuram-se engenheiros. Disponível em: www.cimm.com.br/portal/noticia/exibir_noticia/10189-procuram-se-engenheiros. Acesso em: 24 de julho de 2020.

\title{
MAPPING PROFILE OF PRODUCTION AND CIVIL ENGINEER IN THE LABOR MARKET
}

\begin{abstract}
This study seeks to understand and explain the main and most requested requirements for obtaining a job in the current job market. This analysis aimed to identify skills and attributions inherent to the profession of Civil Engineering and Production Engineering, in order to serve the labor market as professionals who have the practice of developing and transferring the applicability of the acquired knowledge and requested criteria. From the survey of the main job requirements, it was realized that professionals need to be qualified not only in the technical area, to take care of the productive necessities of the company, but also in conduct, as it is important to keep up with the pace of change and assume a position consistent with the same ones. It is expected that, with this analysis, students and engineers will benefit from the information presented here through a survey of the criteria most required by companies for civil and production engineers to obtain a job vacancy in the market of current job.
\end{abstract}

Keywords: engineering, labor market, professional profile. 